\title{
A practical approach to pediatric liver transplantation in hepatoblastoma and hepatocellular carcinoma
}

\author{
Ana M. Calinescu ${ }^{1}$, Geraldine Héry ${ }^{2}$, Jean de Ville de Goyet ${ }^{3, \#}$, Sophie Branchereau ${ }^{2, \#}$ \\ 'Division of Pediatric Surgery, University Center of Pediatric Surgery of Western Switzerland, Geneva University Hospitals, \\ Geneva 1205, Switzerland. \\ ${ }^{2}$ Pediatric Surgery Unit, Bicêtre Hospital, Université Paris-Saclay, Assistance Publique-Hôpitaux de Paris, Le Kremlin-Bicêtre \\ 94270, France. \\ ${ }^{3}$ Department for the Treatment and Study of Pediatric Abdominal Diseases and Abdominal Transplantation, IRCCS ISMETT \\ (Mediterranean Institute for Transplantation and Advanced Specialized Therapies), Palermo 90127, Italy. \\ \#Authors contributed equally.
}

Correspondence to: Dr. Ana M. Calinescu, Division of Pediatric Surgery, University Center of Pediatric Surgery of Western Switzerland, Geneva University Hospitals, 6 Rue Willy Donze, Geneva 1205, Switzerland. E-mail: ana-maria.calinescu@hcuge.ch

How to cite this article: Calinescu AM, Héry G, Goyet JdVd, Branchereau S. A practical approach to pediatric liver transplantation in hepatoblastoma and hepatocellular carcinoma. Hepatoma Res 2021;7:59.

https://dx.doi.org/10.20517/2394-5079.2021.26

Received: 28 Feb 2021 First Decision: 6 May 2021 Revised: 7 Jun 2021 Accepted: 6 Jul 2021 First online: 14 Jul 2021

Academic Editors: Piotr Czauderna, Guang-Wen Cao Copy Editor: Yue-Yue Zhang Production Editor: Yue-Yue Zhang

\begin{abstract}
Progressively, as chemotherapy has become more effective, more children with liver malignancies are amenable to liver transplantation, and indications have expanded from a limited range of cases (mostly hepatoblastoma) to a range of other unresectable malignant liver tumors; as a result, more children with hepatocellular carcinoma are also now proposed to transplantation, even and often outside the Milan criteria, for a cure. Recent series have highlighted that patient and graft survivals after transplantation for hepatoblastoma and hepatocellular carcinoma have improved in the last decade. Although consensus has not yet been reached about transplantation as a possible cure for other tumor types than hepatoblastoma and hepatocellular carcinoma, liver transplantation, generally speaking, has become an important pillar in the management of pediatric liver malignancies. Remaining limitations and inquiries relate to patient selection (in term of selection criteria considering the risk of recurrence), the role and usefulness of chemotherapy after transplantation, or the best immunosuppression strategy to both protect renal function and improve outcome. Although some prospective studies are on the way regarding these aspects, more studies are needed to explore this rapidly changing aspect of care.
\end{abstract}


Keywords: Pediatric liver transplantation, hepatoblastoma, hepatocellular carcinoma

\section{INTRODUCTION}

Despite initial concerns about the risks of exposing oncological patients to immunosuppression, many series have confirmed that the outcome can be excellent even though these children are exposed to immunosuppression after total liver resection and liver transplantation (LT). As a result, LT has expanded as a possible cure and its role has become increasingly important in the management of pediatric liver malignancies. Overall, pediatric liver malignancies account for a tenth of all pediatric LT performed in the United States ${ }^{[1]}$; in Europe, $6 \%$ of all pediatric liver transplantations are performed for an oncological indication within the European Liver Transplant Registry ${ }^{[2]}$. By far, the most frequent pediatric liver malignancies proposed to LT are hepatoblastoma (HBL) and hepatocellular carcinoma (HCC ${ }^{[3]}$. Although the place of LT is growing in the pediatric liver oncology setting, determinants of long-term survival are not very clear yet ${ }^{[4]}$.

Unresectable HBL and HCC have as the only curable alternative total hepatectomy and orthotopic LT; it is a conclusion that was readily available in the early 1990s, with the advent of the first LT for unresectable pediatric liver malignancies ${ }^{[5]}$. The first study providing results for survival was SIOPEL $1^{[6]}$ : it highlighted the importance of proposing LT as a primary strategy and avoiding using it as a last option or as a rescue of previous (failed) surgical attempts; while the former strategy provided excellent results, the latter was associated with poorer prognosis.

Tumor biological behavior has been shown to be not only an important parameter for patient selection but also an essential predictor of the outcome after $\mathrm{LT}^{[7]}$. Although $60 \%-80 \%$ of the patients presenting with HBL are unresectable at presentation and diagnosis ${ }^{[8,9]}$, most respond so well to cisplatin and doxorubicin neoadjuvant chemotherapy that they become "resectable" ${ }^{[3]}$ (up to $85 \%$ of the initially "unresectable" tumors ending resected). Recent series have evidenced that in fact only $20 \%$ of the newly diagnosed patients with HBL eventually will need a $\mathrm{LT}^{[10-13]}$; for these patients, total hepatectomy and LT is the only option and possible cure, with standard/extreme resection less likely to be curative. More interestingly, even in these unresectable cases proposed to LT, it was suggested in $2002^{[7]}$ and confirmed later that good responders to chemotherapy [as judged by dropping levels of alpha-fetoprotein (AFP) and reduction of tumor mass] have a better outcome after LT - this is common sense and can be used as a selection criterion.

HCC in children is rare and has a different biological behavior compared to HBL. In children, it also has a different physiopathology and behavior compared to that in adults, who present HCC mostly on cirrhotic liver, while in children HCC is usually a primary tumor on healthy liver. HCC in children is often unresectable at diagnosis $(80 \%)^{[14]}$; however, multimodal treatment (i.e., chemotherapy and transarterial chemoembolization) has limited effect on HCC, with only $50 \%$ of HCC patients proposed for resection ${ }^{[15]}$, and up to $25 \%$ will eventually need a $\mathrm{LT}^{[15,16]}$.

\section{THE ROLE OF LIVER TRANSPLANTATION IN HEPATOBLASTOMA Indications and contraindications in liver transplantation for hepatoblastoma} Indications

Based on SIOPEL (International Childhood Liver Tumour Strategy Group), indications for LT in HBL patients include: 
(1) Multifocal PRETEXT IV tumors are the typical indication for LT, as by definition all liver sectors are invaded by the tumor or at least by one tumor node. In these cases, the concept of radical resection imposes total hepatectomy; the latter strategy is based on the fact that, although a tumor node (or metastasis) can clear on imaging, viable microscopic tumor residues may persist at the very site that seems "cleared" on imaging. In the latter situation, the only adequate strategy is to radically resect all liver segments that were positive for nodes at diagnosis - although they may be negative on POSTTEXT staging. Controversy persists about the former strategy, with some groups advocating the "pulmonary metastasis" approach, where the clearance of metastatic nodes after chemotherapy allows a "wait and see" policy - allowing to consider liver replacement and transplantation, as metastasis clearance is then considered "absence of active extrahepatic disease" ${ }^{[17-23]}$. In that context, proceeding with partial resection instead of total hepatectomy for PRETEXT IV HBL (and leaving in place liver segments that were positive at diagnosis but cleared during chemotherapy) made sense to a few teams in the last decade. Initial reports were rare and anecdotical (2 cases by Baertschiger et al. ${ }^{[18]}$ in 2010 and 5 cases by Lautz et al. ${ }^{[20]}$ in 2011 ); in the latter series, the only patient who died had partial hepatectomy in the absence of history of metastasis, and one emergency transplant was lifesaving for a child with ischemia after resection. Two other, larger series were reported recently (12 and 21 cases, respectively) (de Freitas Paganoti et al. ${ }^{[19]}$ in 2019 and Fahy et al.$^{[21]}$ in 2020). In the de Freitas Paganoti series, 5/12 had partial hepatectomy (only 1/5 had an extensive hepatectomy), which was followed by a $31.0 \%$ recurrence within three years ${ }^{[19]}$. In the Fahy series, although the outcome is, generally speaking, satisfactory, the cohort description is insufficient to come to a precise conclusion about the children with a PRETEXT IV condition ${ }^{[21]}$. In a recent paper, Uchida et al. ${ }^{[24]}$ reported a series of $24 \mathrm{HBL}(22$ POSTTEXT II or III and 2 POSTTEXT IV) who were proposed for resection $(N=12)$ or LT $(N=12)$ on the basis of a local algorithm based on pre- and peri-operative imaging. Overall, recurrent disease was observed in 2/12 cases after LT and 5/12 cases after resection (2/5 received rescue LT successively), while overall survival was $100 \%$ after LT and $91.7 \%$ after resection (recurrence-free survival being $91.7 \%$ and $58.3 \%$, respectively).

Initial reports of non-transplant approach for PRETEXT IV cases triggered comments from many expert surgeons, worldwide, highlighting the risk of encouraging fewer expert teams to proceed with inappropriate surgical strategies when extreme surgery is associated with higher technical complications rates ${ }^{[23]}$. This has been followed by a series of reports in recent years where there is evidence that:

- PRETEXT IV stage is one of, or "the", most negative prognostic factor for HBL patients ${ }^{[22,25,26]}$.

- Radical resection and efficient chemotherapy are both essential for the cure of HBL, which supports the role of LT for complete disease removal in the case of PRETEXT IV at diagnosis, in order to avoid local recurrence ${ }^{[17,25-27]}$.

- Liver transplantation played an important complementary role in managing HBL children and contributed to the recent increase of survival ${ }^{[24,28,29]}$.

- Although transplantation might be viewed as an "over-treatment" in some cases, it is associated with excellent outcome, while late rescue transplantation (for local recurrence of disease) is the worst scenario, with very poor outcome ${ }^{[6]}$.

The debate is still active $e^{[1,24,30,31]}$, and only dedicated structured prospective studies will be able to answer this delicate question, which cannot be answered at the level of single centers. This might be addressed in the future by the upcoming international protocol "Pediatric Hepatic International Tumour Trial" (PHITT) ${ }^{[32]}$. 
(2) Large solitary PRETEXT IV tumor, unless downstaged after chemotherapy ${ }^{[33]}$.

(3) Large central PRETEXT II and III tumors invading bilaterally the confluence at the porta hepatis or all three hepatic veins ${ }^{[0,34-38]}$.

(4) Local (intra-hepatic) recurrence of HBL after liver resection ${ }^{[3]}$.

(5) Complications of "extreme resections", i.e., early liver failure (due to small-for-size, ischemic damage, or other intraoperative complications) or late complications ${ }^{[6]}$.

The two last categories are defined as "rescue" or "salvage" transplantation, accounting for $15 \%-40 \%$ of all LT performed for HBL in a recent review ${ }^{[17]}$. In the latter situations, LT is associated with poor outcome (30\% survival with most deaths due to recurrence $\left.{ }^{[39]}\right)$, yet LT remains an option in well selected cases ${ }^{[3,38]}$.

\section{Contraindications}

Persistence of macroscopic metastasis (visible on imaging) after chemotherapy and not amenable to surgical excision remains the only absolute contraindication for $\mathrm{LT}^{[39]}$. Although there is no consensus, some consider that response to chemotherapy is a requisite for transplantation, with progression of disease under chemotherapy being a contraindication to $\mathrm{LT}^{[3,8]}$.

In all indications, although the presence of metastases at diagnosis is not a contraindication, the control under chemotherapy (with disappearance at imaging) of the metastasis is mandatory before LT. In cases with some residues at the location of previous metastases, the strategy may consist in surgical resection of these metastases before LT.

The clearance of lung metastasis prior to LT is of utmost importance: a wedge resection is performed the most often; in the case of more than four nodules in the same lobe, lobectomy might be considered as a surgical option ${ }^{[17]}$. Median sternotomy with manual palpation of both lobes might be a valuable option in bilateral lung residual metastasis ${ }^{[40-42]}$. The alternative is sequential surgeries in the case of bilateral involvement ${ }^{[17]}$.

\section{Surgery tips and tricks}

In cases with tumors very close to, encircling or infiltrating, the retro hepatic vena cava, en bloc resection of liver with the vena cava is recommended, with some teams deliberately using this approach for all cases. Venous reconstruction is performed by using donor iliac vein allograft in the case of LT with deceased donation ${ }^{[39]}$. As the latter reconstruction is challenging in the context of living donor LT (lack of donor vein allograft), this situation (that was once considered a contraindication for LT from living related donor ${ }^{[43]}$ ) is nowadays managed by using the jugular vein of the recipient or from the same donor ${ }^{[3,44,45]}$. Other options of using vessels from the same living donor have been proposed (recanalized umbilical vein, external jugular vein, or superficial femoral venous graft) and others have proposed cryopreserved vessels from unrelated donors ${ }^{[45,46]}$. Of note, in the case of large tumors compressing the inferior vena cava with pre-LT sufficient venous return via collaterals to the azygous system, caval vein reconstruction has not been systematically needed $^{[47]}$.

The impact of an early inflow (arterial and portal) exclusion with temporary portocaval shunt was studied for the effect on recurrence: firstly, early inflow interruption might prevent tumor dissemination through the hepatic veins because of surgical manipulations as well as diminish blood losses minimizing the 
requirements for transfusions.

Secondly, temporary portocaval shunting could maintain renal perfusion pressure, which might contribute to the preservation of the postoperative renal function as well as diminish the splanchnic congestion of HBL patients that do not have portosystemic collaterals and thus increase the likelihood of an optimal healing of the Roux en Y loop ${ }^{[48]}$. In this series investigating the early inflow exclusion, a recurrence free survival rate of $88.9 \%$ at one year with preservation of residual renal function was obtained ${ }^{[48]}$.

Finally, an extensive en bloc hepatectomy technique was described in a series with excision of retrocaval retroperitoneal tissue, en bloc lymphadenectomy with peri-choledochal and hepatic hilum nodules along the common hepatic artery, and frozen section from all resection margins; the overall survival in this sevenpatient series was $100 \%$ without recurrence seven years after $\mathrm{LT}^{[49]}$.

\section{Timing of liver transplantation and metastasectomy for hepatoblastoma}

The timing of LT should not be delayed after four weeks after the last course of chemotherapy given the impact on survival; if an expeditious access to deceased donation is not possible, a living related donation should be considered ${ }^{[3,33]}$. A possible option for those who are waiting for a liver from a deceased donor is to plan a new course of chemotherapy if they are not transplanted during the first window of four weeks; these cases are of course not offered a graft during chemotherapy, but this strategy allows a second window of transplantability of one month, after the new course. The latter strategy imposes of course that not all chemotherapy courses are done before the registration of the patient on the list for transplant, but it has been very effective in avoiding exposing the patient to prolonged periods with no chemotherapy and allowing a LT within these time windows.

Children's Oncology Group recommendations in 2016 stated that evaluation for surgery should be done after two cycles of neoadjuvant chemotherapy ${ }^{[50]}$; nevertheless, some tumors continue to regress between Cycles 3 and 4 . Thus, after four rounds of neoadjuvant chemotherapy, $45 \%$ of the tumors are down staged, vs. only $30 \%$ after two cycles; thus, if chemotherapy is well tolerated, it should be continued to allow more patients to undergo successful resections ${ }^{[51]}$.

Clearance for metastasis should be achieved earlier in the chemotherapy course, with SIOPEL 4 recommendations to achieve metastatic control after three induction cycles of chemotherapy ${ }^{[17]}$.

\section{Complications after liver transplantation for hepatoblastoma}

Morbidity after LT in HBL might arise from three origins: (1) chemotherapy toxicity, namely nephrotoxicity, ototoxicity, and sepsis with early discontinuation of adjuvant treatment; (2) surgical morbidity; and (3) immunosupression ${ }^{[50]}$.

At transplantation, the renal function of patients with HBL is reduced because of the toxicity of neoadjuvant chemotherapy; although it can be expected, it has been clearly emphasized that the renal function further deteriorates after $\mathrm{LT}^{[52,53]}$. As the cause for further decline of renal function after LT is directly caused by the sequential and combined toxic effects of chemotherapy and immunosuppression, the strategy has been to use either lower anticalcineurin levels for these patients (compared to standard LT in other indications) ) $^{[3,53]}$ or low-dose anticalcineurin treatment in association with other immunosuppressives (i.e., mycophenolate mofetil $)^{[54]}$ or early conversion to mechanistic target of rapamycin inhibitors ${ }^{[55]}$. 
Overall, morbidity associated to LT might be as high as $67 \%^{[56]}$, with infection being the first cause. This risk may be increased in patients who are exposed to both immunosuppression and chemotherapy; in a monocentric report, infection was identified as the most common morbidity and reached a level of 36\% (cholangitis, bacteremia, central line infections, abdominal collections, and pneumonia) ${ }^{[57]}$. Vascular complications are the second most frequent cause of problems after LT and seem to be higher in patients transplanted for malignancies. Hepatic artery thrombosis is reported to be as high as $28 \%^{[4,1,58]}$. Although some groups do not mention a higher thrombosis risk after LT for HBL patients ${ }^{[59]}$, this might be because these patients do not have liver dysfunction, portal hypertension, or hyper splenism and their coagulation profile is normal at LT, with a possible increased procoagulant activity due to cisplatin. This might justify the systematic use of antithrombotic and/or anticoagulant strategy after LT for HBL ${ }^{[11]}$.

Biliary complications might occur in up to $40 \%$ of the cases, as in other indications for $\mathrm{LT}^{[60,61]}$. In a 19patient series, one patient (5\%) developed a bile duct stricture treated with percutaneous transhepatic cholangioplasty and one bile leak (5\%) was treated by percutaneous drainage ${ }^{[50]}$. Faraj et al.$^{[50]}$ described an incidence of $8 \%$ biliary complications: two bile leaks, one needing a percutaneous drainage and the other laparotomy and drainage. The Japanese national cohort of living donor LT for HBL showed overall 47.2\% surgical complications: $21.7 \%$ biliary complications for the hepaticojejunostomy subgroup and $31.3 \%$ for the duct-to-duct anastomosis subgroup ${ }^{[62]}$.

Other complications such as small bowel obstruction ${ }^{[59]}$ and chylous ascites resolving spontaneously ${ }^{[59]}$ were described more rarely.

Rejection-free survival in HBL recipients with living related donor grafts was $91 \%$ compared to $58 \%$ in controls; it is thought that less immunosuppression is required after LT for hepatoblastoma as a result of diminished immunity after neoadjuvant chemotherapy ${ }^{[3,3,3,53,58]}$. The findings of rejection rates seem different in the case of deceased donation with $50 \%$ and $70 \%$ in two series with 8 and 10 patients, respectively ${ }^{[60,63]}$. A larger study confirmed the difference in rejection rates with $50 \%$ rejection in HBL patients $v s .75 \%$ in a matched biliary atresia LT patient cohort ${ }^{[52]}$. Furthermore, decreased rejection rates persist many months after completion of chemotherapy, probably suggesting an immunomodulatory effect other than just immunosuppression ${ }^{[58]}$. Together with the altered renal function, the decreased rejection rates suggest a need for immunosuppression modulation after LT for HBL.

Post-transplant lymphoproliferative disease was reported in $10 \%$ of patients ${ }^{[0]}$. Nevertheless, none of them died in a United Network Organ Sharing (UNOS) database inquiry ${ }^{[64]}$.

Retransplantation was reported to occur in $10 \%$ of the patients after LT for HBL, because of vascular thrombosis $(60.6 \%)$, primary non-function $(15.2 \%)$, and rejection $(9.1 \%)^{[11,60]}$.

\section{Survival after liver transplantation for hepatoblastoma}

Historically, patients with advanced and metastatic HBL had a 5-year survival of $69 \%$, as reported in $2006^{[65]}$. Almost 10 years later, improved chemotherapy and aggressive transplant listing upgraded 10-year patient survival to $84 \%^{[4,21]}$. A retrospective UNOS analysis identified an overall survival of $76 \%$ with a graft survival of $77 \%$. The three-year overall patient and graft survival was of $85 \%$ starting with $2009^{[8]}$. These results are in line with the SIOPEL 3 and 4 trials that found a $75 \%$ overall survival for patients with unresectable $\mathrm{HBL}^{[22,66]}[$ Table 1]. 
Table 1. Overview of articles looking at survival after pediatric liver transplantation for hepatoblastoma

\begin{tabular}{|c|c|c|c|c|c|}
\hline Author & Nrpx & Period & Patient survival & Graft survival & Follow-up \\
\hline Koneru et al. ${ }^{[102]}, 1991$ & 12 & & $50 \%$ & & $44 \pm 19$ months \\
\hline Tagge et al. ${ }^{[5]}, 1992$ & 6 & 1980-1990 & $83 \%$ & & $1.3 \pm 0.9$ years \\
\hline Al-Quabandy et al. ${ }^{[61]}, 1999$ & 9 & 1991-1997 & $\begin{array}{l}62.5 \% \\
1 \text { year: } 88 \% \\
5 \text { years: } 65 \%\end{array}$ & & 22 months (9-82) \\
\hline Reyes et al. ${ }^{[90]}, 2000$ & 11 & 1989-1998 & $\begin{array}{l}1 \text { year: } 92 \% \\
3 \text { years: } 83 \% \\
5 \text { years: } 83 \%\end{array}$ & $\begin{array}{l}1 \text { year: } 92 \% \\
3 \text { years: } 83 \% \\
5 \text { years: } 83 \%\end{array}$ & 76 months (18-146) \\
\hline Molmenti et al. ${ }^{[10]}, 2001$ & 8 & 1984-1999 & $63 \%$ & & 6.8 years \\
\hline Pimpalwar et al. ${ }^{[7]}, 2002$ & 12 & $1991-2000$ & $\begin{array}{l}\text { Good responders: } 100 \% \\
\text { Bad responders: } 60 \% \\
\text { Rescue transplant: } 50 \%\end{array}$ & $86 \%$ & 3.7 years \\
\hline Srinivasan et al. ${ }^{[78]}, 2002$ & 13 & $1992-2001$ & $100 \%$ & & 33 months (1-108) \\
\hline Cillo et al. ${ }^{[103]}, 2003$ & 7 & $1990-2003$ & $\begin{array}{l}1 \text { year: } 83.3 \% \\
3 \text { years: } 83.3 \% \\
5 \text { years: } 56 \%\end{array}$ & & 41.4 months (3-108) \\
\hline Tiao et al. ${ }^{[63]}, 2004$ & 8 & $1986-2002$ & $87.5 \%$ & & \\
\hline Mejia et al. ${ }^{[60]}, 2005$ & 10 & $1985-2003$ & $70 \%$ & & $10.8 \pm 5.4$ years \\
\hline Kasahara et al. ${ }^{[76]}, 2005$ & 14 & $1990-2004$ & $65.5 \%$ & $78.6 \%$ & 42 months \\
\hline Otte et al. ${ }^{[33]}, 2005$ & 147 & & $\begin{array}{l}6 \text { years: } 82 \% \\
30 \% \text { for rescue liver transplantation }\end{array}$ & & 38 months (1-121) \\
\hline Casas-Melley et al. ${ }^{[104]}, 2007$ & 8 & $2001-2005$ & $75 \%$ & & 7-53 months \\
\hline Faraj et al. ${ }^{[59]}, 2008$ & 25 & $1993-2007$ & $\begin{array}{l}1 \text { year: } 91 \% \\
5 \text { years: } 77.6 \% \\
10 \text { years: } 77.6 \%\end{array}$ & $\begin{array}{l}1 \text { year: } 91 \% \\
5 \text { years: } 77.6 \% \\
10 \text { years: } 77.6 \%\end{array}$ & 60 months (1-179) \\
\hline Browne et al. ${ }^{[73]}, 2008$ & 14 & $1990-2004$ & $71 \%$ & & 46 months \\
\hline Malek et al. ${ }^{[56]}, 2010$ & 23 & $1990-2007$ & $95 \%$ & & \\
\hline Hery et al. ${ }^{[105]}, 2011$ & 13 & $2001-2009$ & $\begin{array}{l}77 \% \\
1 \text { year: } 100 \% \\
4 \text { years: } 83.3 \%\end{array}$ & & 3.3 years ( $1-5$ years) \\
\hline Barrena et al. ${ }^{[106]}, 2011$ & 15 & $1991-2009$ & $1-5-10$ years: $93.3 \% \pm 6.4 \%$ & & $4.8 \pm 2.9$ years \\
\hline Cruz et al. ${ }^{[11]}, 2012$ & 332 & $1988-2010$ & $\begin{array}{l}1 \text { year: } 84 \%, \\
3 \text { years: } 75.7 \% \\
5 \text { years: } 73.1 \%\end{array}$ & $\begin{array}{l}1 \text { year: } 80.2 \% \\
3 \text { years: } 70.7 \% \\
5 \text { years: } 68.1 \%\end{array}$ & \\
\hline McAteer et al. ${ }^{[12]}, 2013$ & 53 & $1998-2009$ & 5 years: $86.5 \%$ & & \\
\hline Ruth et al. ${ }^{[52]}, 2014$ & 20 & $1991-2008$ & 2 years: $75 \%$ & & 7 years and 6 months \\
\hline Sakamoto et al. ${ }^{[62]}, 2014$ & 39 & $1996-2009$ & $\begin{array}{l}3 \text { years: } 84.3 \% \\
5 \text { years: } 77.3 \% \\
10 \text { years: } 77.3 \%\end{array}$ & & \\
\hline Pham et al. ${ }^{[4]}, 2015$ & 30 & $1997-2014$ & $84 \%$ & $83 \%$ & \\
\hline Kueht et al. ${ }^{[50]}, 2016$ & 19 & $2000-2013$ & $\begin{array}{l}30 \text { days: } 94.7 \% \\
1 \text { year: } 86.1 \% \\
5 \text { years: } 73.8 \%\end{array}$ & & \\
\hline Uchida et al. ${ }^{[48]}, 2016$ & 12 & $2005-2015$ & $92 \%$ & $92 \%$ & 2.7 years \\
\hline Umeda et al. ${ }^{[68]}, 2017$ & 24 & $1997-2015$ & 5 years: $69.6 \% \pm 9.7 \%$ & & \\
\hline Kirnap et al. ${ }^{[107]}, 2017$ & 6 & $2001-2015$ & $83.3 \%$ recurrence free & & 29.9 months \\
\hline Ezekian et al. ${ }^{[108]}, 2018$ & 279 & & $\begin{array}{l}1 \text { year: } 89.1 \% \\
5 \text { years : } 82.6 \%\end{array}$ & & \\
\hline Hamilton et al. ${ }^{[8]}, 2018$ & 376 & $1987-2012$ & $76 \%$ & $77 \%$ & \\
\hline Isono et al. ${ }^{[79]}, 2018$ & 8 & $2002-2016$ & $75 \%$ & & 77 months \\
\hline Ramos-Gonzalez et al. ${ }^{[57]}, 2018$ & 25 & $2001-2015$ & 10 years: $84 \%$ & $\begin{array}{l}1 \text { year: } 96 \% \\
3 \text { years: } 87 \% \\
5 \text { years: } 80 \%\end{array}$ & 4,6 years $(2.6-8.6)$ \\
\hline Uchida et al. ${ }^{[24]}, 2018$ & 12 & $2011-2016$ & $100 \%$ & & 38 months (9-75) \\
\hline Triana Junco et al. ${ }^{[69]}, 2018$ & 31 & $1992-2017$ & $\begin{array}{l}1 \text { year: } 93.3 \% \pm 4.6 \% \\
5 \text { years: } 86.4 \% \pm 6.3 \%\end{array}$ & & 9 years $(1-25)$ \\
\hline
\end{tabular}




\begin{tabular}{lllll} 
Fahy et al. $^{[21]}, 2019$ & 60 & $2001-2015$ & $93 \%$ & 78 months \\
Okur et al. ${ }^{[109]}, 2019$ & 10 & $2009-2014$ & $90 \%$ & 13.5 months $(8-120)$ \\
Feng et al. ${ }^{[110]}, 2019$ & 93 & $2004-2016$ & 10 years: $87.2 \%$ & 60 months \\
Herden et al. ${ }^{[49]}, 2019$ & 7 & $2007-2012$ & $100 \%$ & 7.1 years $(5.7-10.7)$ \\
Laufermann et al. $^{[80]}, 2019$ & 21 & $2005-2018$ & 5 years: $90 \%$ & 22 months $(0-127)$ \\
\hline
\end{tabular}

In an attempt to reduce the time between diagnosis and LT, an early referral practice was introduced in the late 2000s, with a parallel evaluation of resection and potential LT; the major success of this approach was to reduce the number of secondary $\mathrm{LT}^{[50]}$.

Survival in the case of "rescue LT" seems worse at five years, at less than $30 \%^{[12,63]}$. Overall, a literature review identified a survival of $41 \%$ for rescue $\mathrm{LT}^{[67]}$. A Japanese study identified a $72 \% 5$-year overall survival in a series of 11 "rescue LT" patients ${ }^{[68]}$.

LT outcomes for HBL patients with synchronous lung metastasis eradicated before LT are excellent at one and five years, $93.3 \% \pm 4.6 \%$ and $86.4 \% \pm 6.3 \%$, respectively ${ }^{[69]}$. Single pulmonary metastasis and patients with lesions visible only on $\mathrm{CT} v$ s. lesions visible on both $\mathrm{CT}$ and chest X-ray have a better outcome ${ }^{[35,70]}$.

The need for chemotherapy after LT is a matter of debate: a review did not identify a statistically significant difference in survival rates with and without post-LT chemotherapy ${ }^{[6]}$, nor did the Pediatric Liver Unresectable Tumour Observatory registry ${ }^{[7]}$. Some studies promote its use in the case of vascular invasion or large proportion of viable tumor in the explanted liver ${ }^{[72]}$. The survival rates seem improved even if statistical significance was not reached in the series inquiring into this issue ${ }^{[73]}$.

\section{Recurrence after liver transplantation for hepatoblastoma}

Tumor recurrence is the most frequent cause of death: up to 50\% of the patients with tumor recurrence die, usually within two years after $\mathrm{LT}^{[21,59,65]}$; the longest interval between LT and recurrent HBL was 2.8 years in the Japanese national survey ${ }^{[62]}$. A review identified $14.6 \%$ of the relapse HBL patients after LT to be alive and disease free ${ }^{[68]}$.

Recurrence after LT for HBL presents itself mainly as metastatic disease and is encountered in as high as $40 \%$ of the cases $^{[11,60]}$. It is thought to correspond to a more aggressive type of tumor to which transplantation will not respond better than initial resection ${ }^{[73]}$. This seems to be supported by the findings of Khan et al..$^{[74]}$ : in their institutional review, none of the HBL patients had a complete tumor response. As a surrogate marker for recurrence, AFP levels after LT could be a valuable adjunct, with a series reporting a normalization of AFP values in the subgroup of patients without recurrence and staying increased or even further increasing in patients with recurrence ${ }^{[75]}[$ Table 2]. In cases with limited and regional relapse (typically a single node in the abdominal area), re-resection strategy may offer a cure (personal communication $)^{[2]}$.

The long-term survival of patients having a LT for HBL shows the following risk factors for tumor recurrence: PRETEXT IV, tumor rupture, higher time spent within the waiting list (15 days vs. 31 days), older age (78 months vs. 48 months) ${ }^{[4]}$, macroscopic vascular invasion, extrahepatic lesions at the time of LT, presence of viable tumor (tumor necrosis less than 50\% and high preoperative AFP values), tumor shrinkage rate of $\leq 30 \%$, and high AFP at diagnosis and $\mathrm{LT}^{[11,59,62,76,24]}$. 
Table 2. Risk factors associated with hepatoblastoma recurrence after pediatric liver transplantation

\begin{tabular}{ll}
\hline 1. Anatomic tumor related factors & Hepatic vein invasion \\
& PRETEXT IV \\
2. Patient related factors & Age at presentation \\
& Pretransplant metastatic disease \\
3. Pretransplant treatment related factors & Serum AFP at time of LT \\
& Percentage of decline AFP from diagnosis to LT \\
& Response to chemotherapy \\
& $<50 \%$ tumor necrosis \\
4. Transplant related factors & Time to transplant \\
& Segmental donor graft \\
& Salvage LT \\
\hline
\end{tabular}

Previous lung metastases, initially considered as favoring recurrence, were recently proved not to be risk factors for tumor recurrence ${ }^{[77]}$. In the case of limited recurrence, especially if recurrence is at sites previously diagnosed and clearing under chemotherapy, an aggressive surgical approach and resection has been proposed; the latter outcome may be favorable as these recurrences are in fact local relapse rather than new secondaries associated to systemic relapse ${ }^{[62]}$.

The 3-year recurrence free survival was reported to be $78 \%$ in a cohort of 15 patients with rescue $\mathrm{LT}^{[62]}$. Later, an 11-patient Japanese series reported a recurrence rate of only $27 \%$ in this subgroup of rescue $\mathrm{LT}^{[68]}$.

Segmental grafts (from cadaveric or living donors) versus cadaveric whole liver grafts seem also to make $\mathrm{HBL}$ recipients more prone to recurrence; whether this difference is due to the cava-sparing hepatectomy technique is not clear yet ${ }^{[8,11]}$.

Overall, longer waiting list time was found to be associated with higher recurrence risk, a rather intuitive finding ${ }^{[4]}$.

Post-transplantation chemotherapy seems to decrease the tumor recurrence ${ }^{[6,73,78]}$. It is thus recommended, although it might be difficult to practically implement because of complications after transplantation ${ }^{[73]}$. There is actually no uniform policy for the post-LT chemotherapeutic regimen and its clinical relevance is still debated ${ }^{[68]}$.

In recurrent HBL after LT, the increasing AFP levels pretransplant despite continued neoadjuvant chemotherapy led to the conclusion that LT should be performed before the tumor acquires chemoresistance and thus before the decrease in AFP levels reaches a plateau ${ }^{[79]}$. Patients with higher pre-LT AFP also exhibited a higher risk for non-curable relapse than patients benefiting from LT at lower $\mathrm{AFP}^{[80]}$.

\section{THE ROLE OF LIVER TRANSPLANTATION IN HEPATOCELLULAR CARCINOMA Indications and contraindications in liver transplantation for hepatocellular carcinoma}

Indications

The first study inquiring the role of LT as primary surgical treatment for HCC without extrahepatic involvement was from Czauderna et al. ${ }^{\left[{ }^{[1]}\right.}$ in the early 2000s. They highlighted that the results of the conventional resective approach in cases with resectable tumors were far less favorable than those who benefited from LT for unresectable masses. This opened a window of opportunity for proposing LT as a curative strategy for children with unresectable HCC. Although there is still no consensus about the criteria for proposing LT to manage HCC in children, the results of Czauderna et al.$^{[1]}$ emphasize that HCC in children is different from that in adults. Hence, an opposite strategy to that of HCC in adults could be 
followed: while HCC are selected for LT in adults with smaller tumors, in term of mass and/or number (the Milan criteria) $)^{[82]}$, there are no well-defined pediatric criteria to contraindicate the HCC candidate for LT $^{[82]}$ as follows:

(1) Unlike adults, HCC occurs in children mainly in the absence of concomitant cirrhosis ${ }^{[12]}$, and this is one reason for a different selection strategy. The Milan criteria, developed for adults with cirrhotic liver disease, have been adopted by some centers (one tumor of $5 \mathrm{~cm}$ or less or no more than three nodules of $3 \mathrm{~cm}$ or less) in an effort to improve survival rates ${ }^{[3]}$. The more liberal criteria of the University of California San Francisco (UCSF) are partially adopted by some other centers ${ }^{[72]}$. More extensive criteria, "up to seven" (number of lesions and diameter), show a minimal decrease in survival rate, from $71 \%$ to $65 \%{ }^{[83]}$.

(2) The practice guidelines of the American Association for Transplantation and the North American Society for Pediatric Gastroenterology, Hepatology and Nutrition recommend an individualized indication for LT for each patient ${ }^{[84]}$. Basically, LT is recommended for HCC patients in the case of no extrahepatic tumor or gross vascular invasion on radiological imaging, irrespective of the number or size of the lesions ${ }^{[84]}$.

(3) In Japan, the Japanese Organ Transplantation Act proposed the rule of 5-5-500: tumor size $\leq 5 \mathrm{~cm}$ diameter, tumor number $\leq 5$, and AFP level $\leq 500 \mathrm{ng} / \mathrm{mL}$ for living donor LT for HCC in adults ${ }^{[85]}$. Modifications of this rule were adopted (Kyoto criteria, Tokyo 5-5 rule, and Kyushu University) with larger inclusion of patients but lower survival and higher recurrence rates ${ }^{[85]}$.

Of note, none of these are validated in pediatric $\mathrm{HCC}^{[86]}$. A general consensus is to offer LT for unresectable HCC patients and no extrahepatic disease ${ }^{[87]}$, while LT should be considered even for patients with HCC PRETEXT I or II in selected cases ${ }^{[88]}$.

\section{Contraindications}

Because HCC in children is different to that in adults and the Milan criteria do not strictly apply, proposing LT in pediatric HCC remains a delicate choice and strategy: patients should be evaluated individually within multidisciplinary teams including oncologists, hepatologists, pediatric surgeons, and pediatric liver transplant surgeon ${ }^{[89]}$. As evidenced for HBL, tumor behavior during chemotherapy and downsizing may be important elements to consider for indicating LT as a curative option.

Major vascular venous invasion (especially the extrahepatic invasion of vena cava and portal vein trunk) is a contraindication for transplantation in HCC due to poor long-term prognosis - unless neoadjuvant chemotherapy achieves an evident down staging ${ }^{[90]}$. As for HBL, the presence of extrahepatic tumor is a contraindication for transplantion ${ }^{[14]}$. Fibrolamellar variant of HCC constitutes the third contraindication ${ }^{[91]}$.

\section{Survival after liver transplantation for hepatocellular carcinoma}

HCC seems to behave differently in children than in adults as LT for lesions outside the Milan and UCSF criteria still lead to excellent long-term survival ${ }^{[4]}$. A Surveillance, Epidemiology and End Results database review identified an $89 \%$ 4-year overall survival with $27.6 \%$ of the patient most likely outside and $34.5 \%$ definitely outside the Milan criteria ${ }^{[92]}$. A retrospective UNOS database analysis identified an overall patient and graft survival of $63 \%$ with 3 -year overall patient and graft survival of $84 \%$ starting with $2009^{[8]}$ [Table 3].

Poor prognostic factors for HCC are as follows: metastasis, large tumor size, lymph node extension, and macroscopic vascular invasion ${ }^{[1,3]}[$ Table 4$]$. 
Table 3. Overview of articles looking at survival after pediatric liver transplantation for hepatocellular carcinoma

\begin{tabular}{|c|c|c|c|c|}
\hline Author & Nrpx & Period & Survival & Follow-up \\
\hline Tagge et al. ${ }^{[5]}, 1992$ & 9 & $1980-1990$ & $44 \%$ & $2.3 \pm 1.2$ \\
\hline Reyes et al. ${ }^{[90]}, 2000$ & 19 & 1989-1998 & $\begin{array}{l}1 \text { year: } 79 \% \\
3 \text { years: } 73 \% \\
5 \text { years: } 68 \%\end{array}$ & 19.5 months (6-58) \\
\hline Ozcay et al. ${ }^{[94]}, 2006$ & 6 & $2001-2005$ & $100 \%$ & $17.7 \pm 6$ months \\
\hline Arikan et al. $.^{[11]}, 2006$ & 7 & $1997-2003$ & $1-4$ years: $72 \%$ & 36 months \\
\hline Sevmis et al. ${ }^{[112]}, 2008$ & 9 & $2001-2007$ & $100 \%$ graft and patient & $19.8 \pm 10.6$ months \\
\hline Ismail et al. ${ }^{[88]}, 2009$ & 11 & $1990-2007$ & $72 \%$ & 43 months (32-85) \\
\hline Malek et al. ${ }^{[56]}, 2010$ & 6 & $1990-2007$ & $67 \%$ & \\
\hline Romano et al. ${ }^{[113]}, 2011$ & 10 & 1997-2009 & $80 \%$ & 4 years \\
\hline McAteer et al. ${ }^{[12]}, 2013$ & 20 & $1998-2009$ & 5 years: $85.3 \%$ & \\
\hline Pham et al. ${ }^{[4]}, 2015$ & 10 & 1997-2014 & $\begin{array}{l}72 \% \text { patient } \\
85 \% \text { graft }\end{array}$ & \\
\hline Triana et al. ${ }^{[87]}, 2016$ & 10 & 1994-2015 & $20 \%$ & 78 months (66-90) \\
\hline Vinayak et al. ${ }^{[1]}, 2017$ & 25 & $1981-2014$ & $36 \%$ & \\
\hline Baumann et al. ${ }^{[93]}, 2018$ & 175 & $1985-2012$ & $\begin{array}{l}1 \text { year patient: } 81.2 \% \\
2 \text { years patient: } 68.3 \% \\
5 \text { years patient: } 57.6 \% \\
1 \text { year graft-2-5: } 73.6 \% \\
2 \text { years graft: } 58.5 \% \\
5 \text { years graft: } 56.3 \%\end{array}$ & \\
\hline Ezekian et al. ${ }^{[108]}, 2018$ & 49 & $2010-2018$ & $\begin{array}{l}1 \text { year: } 94.7 \% \\
5 \text { years: } 80.8 \%\end{array}$ & \\
\hline Hamilton et al. ${ }^{[8]}, 2018$ & 85 & $1987-2012$ & 5 years patient and graft: $63 \%$ & \\
\hline Weiss et al. ${ }^{[114]}, 2018$ & 6 & $2005-2013$ & $83 \%$ & 3.4-11 years \\
\hline Ziogas et al. ${ }^{[92]}, 2020$ & 34 & 2004-2015 & $\begin{array}{l}1 \text { year: } 96.2 \% \\
3 \text { years: } 88 \% \\
5 \text { years: } 88 \%\end{array}$ & 52.9 months (46.7-59) \\
\hline D'Souza et al. ${ }^{[82]}, 2020$ & 11 & 2004-2015 & $82 \%$ & 58.8 months (26.5-157.6) \\
\hline
\end{tabular}

Table 4. Risk factors associated with hepatocellular carcinoma outcome after pediatric liver transplantation

\begin{tabular}{ll}
\hline 1. Anatomic tumor related factors & $\begin{array}{l}\text { PRETEXT } \\
\text { Vascular and lymph node invasion } \\
\text { Size of tumor }\end{array}$ \\
& $\begin{array}{l}\text { Age at presentation } \\
\text { 2. Patient related factors }\end{array}$ \\
& $\begin{array}{l}\text { Metastatic disease } \\
\text { Response to chemotherapy }\end{array}$ \\
3. Pretransplant treatment related factors & Sorafenib use \\
4. Post-transplant related factors & \\
\hline
\end{tabular}

Younger age was found as a prognostic factor for a better survival in LT after $\mathrm{HCC}^{[93]}$.

Survival seems worse for HCC newly diagnosed in a healthy liver than HCC diagnosed during surveillance for a chronic disease or incidentally discovered in the explants of LT for another disease ${ }^{[3,93,94]}$.

The role of chemotherapy in pediatric HCC is still debated: although it responds to chemotherapy more than adult HCC, pediatric HCC for which chemotherapy was administrated failed to show an improved survival in both adjuvant and neoadjuvant setting ${ }^{[89,92]}$. Data from the PHITT that administers neoadjuvant chemotherapy to patients with unresectable HCC at diagnosis will eventually answer this question ${ }^{[89]}$. Survival rates were higher for patients responding to preoperative chemotherapy ${ }^{[8]}$. 
The use of sorafenib has shown better survival rates in the adult population, demonstrating an improvement in median overall survival (10.7 months vs. 7.9 months) ${ }^{[95]}$; in children, few data have been published in this respect ${ }^{[15]}$.

Overall survival was not different in subgroups according to $5 \mathrm{~cm}$ cut off, vascular invasion, and the Milan criteria $^{[89]}$. No differences in survival have been found when comparing living donors to deceased donors ${ }^{[96]}$.

When studying treatment choice, a 21-patient series comparing outcomes for resection and chemotherapy $v s$. LT in pediatric HCC reveals a superior survival (72\%vs. 40\%) in the LT subgroup, pointing out the need for the early evaluation of transplantability of pediatric HCC patients in the treatment course ${ }^{[88]}$.

\section{Recurrences after liver transplantation for hepatocellular carcinoma}

During surgery for HCC, operative manipulation, increased intraoperative blood loss, and blood transfusions are thought to be potential mechanisms for tumor recurrence ${ }^{[97,98]}$.

The risk factors identified for recurrence of HCC are as follows: tumor stage, vascular invasion, and lymph node involvement. In the long term, older age and metastatic disease were additionally identified ${ }^{[1,4,90]}$.

Few series describe the outcome of HCC patients with macrovascular invasion undergoing LT; a 5-year recurrence free survival of $89 \%$ is reported in a 10-patient series ${ }^{[99]}$.

Unlike adults, the risk for recurrence is not higher if patients do not meet the Milan criteria ${ }^{[8]}$. Given higher recurrence rates of HCC after surgical resection than after LT, it is hypothesized that LT should be liberalized even for resectable tumors ${ }^{[8]}$.

Of note, no recurrence was identified in the patients for whom HCC was incidentally discovered in the liver explant ${ }^{[1]}$.

The recurrences and impact on survival of deceased versus living LT has been studied in the adult literature but very few data are available within the pediatric literature ${ }^{[100]}$.

Whether corticosteroids and calcineurin inhibitors increase the likelihood of tumor recurrence after LT for HCC is not clear yet; it is the reason for some centers to privilege the use of sirolimus, as it has been shown to inhibit the growth of a wide variety of tumors ${ }^{[3]}$. An adult study did not show an improved long-term recurrence free survival beyond five years, but it increased the overall survival and the recurrence-free survival in the first three to five years after $\mathrm{LT}^{[101]}$.

\section{ONGOING AREAS OF RESEARCH}

Pediatric LT has a growing place in the management of unresectable HBL and HCC. There are still unanswered questions concerning the role of post-LT chemotherapy for HBL, immunosuppression modulation, and the correlation of the AFP levels after LT with survival. Besides an obvious need for validated LT criteria for pediatric HCC patients, the impact of chemotherapy and waiting time for LT are still to be studied. 


\section{CONCLUSION}

Pediatric LT in the oncological setting has evolved during the last two decades into an effective procedure for a selected subgroup of patients. Indications are quite clear in HBL but still need validation in pediatric HCC patients. This review focuses on indications and limitations in the LT treatment of unresectable pediatric HBL and HCC. The ongoing PHITT trial will probably provide evidence-based guidelines for the LT management of pediatric patients with unresectable HBL and HCC.

\section{DECLARATIONS}

\section{Authors' contributions}

Made substantial contributions to conception and design of the study, performed data analysis and interpretation, finally approved the version to be published and agreed to be accountable for all aspects of the work: Calinescu AM, Héry G, Branchereau S, de Ville de Goyet J

Performed the draft: Calinescu AM, de Ville de Goyet J

Critical revision of the intellectual content: de Ville de Goyet J, Branchereau S, Héry G

\section{Availability of data and materials}

Not applicable.

\section{Financial support and sponsorship}

None.

\section{Conflicts of interest}

All authors declared that there are no conflicts of interest.

\section{Ethical approval and consent to participate}

Not applicable.

\section{Consent for publication}

Not applicable.

\section{Copyright}

(c) The Author(s) 2021.

\section{REFERENCES}

1. Vinayak R, Cruz RJ Jr, Ranganathan S, et al. Pediatric liver transplantation for hepatocellular cancer and rare liver malignancies: US multicenter and single-center experience (1981-2015). Liver Transpl 2017;23:1577-88. DOI PubMed PMC

2. Registry ELT. Available from: http://www.eltr.org. [Last accessed on 14 Jul 2021].

3. Stringer MD. The role of liver transplantation in the management of paediatric liver tumours. Ann R Coll Surg Engl 2007;89:12-21. DOI PubMed PMC

4. Pham TA, Gallo AM, Concepcion W, Esquivel CO, Bonham CA. Effect of liver transplant on long-term disease-free survival in children with hepatoblastoma and hepatocellular cancer. JAMA Surg 2015;150:1150-8. DOI PubMed

5. Tagge EP, Tagge DU, Reyes J, et al. Resection, including transplantation, for hepatoblastoma and hepatocellular carcinoma: Impact on survival. J Pediatr Surg 1992;27:292-7. DOI PubMed PMC

6. Otte JB, Pritchard J, Aronson DC, et al; International Society of Pediatric Oncology (SIOP). Liver transplantation for hepatoblastoma: results from the International Society of Pediatric Oncology (SIOP) study SIOPEL-1 and review of the world experience. Pediatr Blood Cancer 2004;42:74-83. DOI PubMed

7. Pimpalwar AP, Sharif K, Ramani P, et al. Strategy for hepatoblastoma management: Transplant versus nontransplant surgery. $J$ Pediatr Surg 2002;37:240-5. DOI PubMed

8. Hamilton EC, Balogh J, Nguyen DT, Graviss EA, Heczey AA, Austin MT. Liver transplantation for primary hepatic malignancies of childhood: the UNOS experience. J Pediatr Surg ;2017:163-8. DOI PubMed

9. Trobaugh-Lotrario AD, Meyers RL, O'Neill AF, Feusner JH. Unresectable hepatoblastoma: current perspectives. Hepat Med 2017;9:1-6. DOI PubMed PMC

10. Molmenti E, Nagata D, Roden J, et al. Liver transplantation for hepatoblastoma in the pediatric population. Transplant Proc 
2001;33:1749. DOI PubMed

11. Cruz RJ Jr, Ranganathan S, Mazariegos G, et al. Analysis of national and single-center incidence and survival after liver transplantation for hepatoblastoma: new trends and future opportunities. Surgery 2013;153:150-9. DOI PubMed

12. McAteer JP, Goldin AB, Healey PJ, Gow KW. Surgical treatment of primary liver tumors in children: outcomes analysis of resection and transplantation in the SEER database. Pediatr Transplant 2013;17:744-50. DOI PubMed

13. Superina R, Bilik R. Results of liver transplantation in children with unresectable liver tumors. J Pediatr Surg 1996;31:835-9. DOI PubMed

14. Ng K, Mogul DB. Pediatric liver tumors. Clin Liver Dis 2018;22:753-72. DOI PubMed

15. Kohorst MA, Warad DM, Matsumoto JM, et al. Management of pediatric hepatocellular carcinoma: a multimodal approach. Pediatr Transplant 2017;21:e13007. DOI PubMed

16. Sindhi R, Rohan V, Bukowinski A, et al. Liver transplantation for pediatric liver cancer. Cancers (Basel) 2020;12:720. DOI PubMed PMC

17. Lake CM, Tiao GM, Bondoc AJ. Surgical management of locally-advanced and metastatic hepatoblastoma. Semin Pediatr Surg 2019;28:150856. DOI PubMed

18. Baertschiger RM, Ozsahin H, Rougemont AL, et al. Cure of multifocal panhepatic hepatoblastoma: is liver transplantation always necessary? J Pediatr Surg 2010;45:1030-6. DOI PubMed

19. Freitas Paganoti G, Tannuri ACA, Dantas Marques AC, Torres RR, Mendes Gibelli NE, Tannuri U. Extensive hepatectomy as an alternative to liver transplant in advanced hepatoblastoma: a new protocol used in a pediatric liver transplantation center. Transplant Proc 2019;51:1605-10. DOI

20. Lautz TB, Ben-Ami T, Tantemsapya N, Gosiengfiao Y, Superina RA. Successful nontransplant resection of POST-TEXT III and IV hepatoblastoma. Cancer 2011;117:1976-83. DOI PubMed

21. Fahy AS, Shaikh F, Gerstle JT. Multifocal hepatoblastoma: what is the risk of recurrent disease in the remnant liver? J Pediatr Surg 2019;54:1035-40. DOI PubMed

22. Meyers RL, Tiao G, de Ville de Goyet J, Superina R, Aronson DC. Hepatoblastoma state of the art: pre-treatment extent of disease, surgical resection guidelines and the role of liver transplantation. Curr Opin Pediatr 2014;26:29-36. DOI PubMed

23. Czauderna P, Otte JB, Roebuck DJ; International Childhood Liver Tumors Strategy Group (SIOPEL). Comments on surgical treatment of locally advanced hepatoblastoma. Cancer 2012;118:4092-3; author reply 4094. DOI PubMed

24. Uchida H, Sakamoto S, Sasaki K, et al. Surgical treatment strategy for advanced hepatoblastoma: resection versus transplantation. Pediatr Blood Cancer 2018;65:e27383. DOI PubMed

25. Czauderna P, Haeberle B, Hiyama E, et al. The Children's Hepatic tumors International Collaboration (CHIC): Novel global rare tumor database yields new prognostic factors in hepatoblastoma and becomes a research model. Eur J Cancer 2016;52:92-101. DOI PubMed PMC

26. Maibach R, Roebuck D, Brugieres L, et al. Prognostic stratification for children with hepatoblastoma: the SIOPEL experience. Eur J Cancer 2012;48:1543-9. DOI PubMed

27. Meyers RL, Maibach R, Hiyama E, et al. Risk-stratified staging in paediatric hepatoblastoma: a unified analysis from the Children's Hepatic tumors International Collaboration. Lancet Oncol 2017;18:122-31. DOI PubMed PMC

28. Koh KN, Namgoong JM, Yoon HM, et al. Recent improvement in survival outcomes and reappraisal of prognostic factors in hepatoblastoma. Cancer Med 2021;10:3261-73. DOI PubMed PMC

29. Zsíros J, Maibach R, Shafford E, et al. Successful treatment of childhood high-risk hepatoblastoma with dose-intensive multiagent chemotherapy and surgery: final results of the SIOPEL-3HR study. J Clin Oncol 2010;28:2584-90. DOI PubMed

30. Fonseca A, Gupta A, Shaikh F, et al. Extreme hepatic resections for the treatment of advanced hepatoblastoma: are planned close margins an acceptable approach? Pediatr Blood Cancer 2018;65:e26820. DOI PubMed

31. Fuchs J, Cavdar S, Blumenstock G, et al. POST-TEXT III and IV hepatoblastoma: extended hepatic resection avoids liver transplantation in selected cases. Ann Surg 2017;266:318-23. DOI PubMed

32. Aronson DC, Meyers RL. Malignant tumors of the liver in children. Semin Pediatr Surg 2016;25:265-75. DOI PubMed

33. Otte JB, de Ville de Goyet J, Reding R. Liver transplantation for hepatoblastoma: indications and contraindications in the modern era. Pediatr Transplant 2005;9:557-65. DOI PubMed

34. Perilongo G, Shafford E, Plaschkes J. SIOPEL trials using preoperative chemotherapy in hepatoblastoma. Lancet Oncol 2000;1:94100. DOI PubMed

35. Brown J, Perilongo G, Shafford E, et al. Pretreatment prognostic factors for children with hepatoblastoma - results from the International Society of Paediatric Oncology (SIOP) Study SIOPEL 1. Eur J Cancer 2000;36:1418-25. DOI PubMed

36. Bucuvalas JC, Alonso E. Long-term outcomes after liver transplantation in children. Curr Opin Organ Transplant 2008;13:247-51. DOI PubMed

37. Perilongo G, Shafford E, Maibach R, et al; International Society of Paediatric Oncology-SIOPEL 2. Risk-adapted treatment for childhood hepatoblastoma. final report of the second study of the International Society of Paediatric Oncology--SIOPEL 2. Eur $J$ Cancer 2004;40:411-21. DOI PubMed

38. Aronson DC, Schnater JM, Staalman CR, et al. Predictive value of the pretreatment extent of disease system in hepatoblastoma: results from the International Society of Pediatric Oncology Liver Tumor Study Group SIOPEL-1 study. J Clin Oncol 2005;23:124552. DOI PubMed

39. Otte JB, de Ville de Goyet J. The contribution of transplantation to the treatment of liver tumors in children. Semin Pediatr Surg 2005;14:233-8. DOI PubMed 
40. Fuchs J, Seitz G, Ellerkamp V, et al. Analysis of sternotomy as treatment option for the resection of bilateral pulmonary metastases in pediatric solid tumors. Surg Oncol 2008;17:323-30. DOI PubMed

41. Gupta AA, Gerstle JT, Ng V, et al. Critical review of controversial issues in the management of advanced pediatric liver tumors. Pediatr Blood Cancer 2011;56:1013-8. DOI PubMed

42. Takahashi N, Yamada Y, Hoshino K, et al. Living donor liver re-transplantation for recurrent hepatoblastoma in the liver graft following complete eradication of peritoneal metastases under indocyanine green fluorescence imaging. Cancers (Basel) 2019;11:730. DOI PubMed PMC

43. Kalicinski P, Ismail H, Broniszczak D, et al. Non-resectable hepatic tumors in children - role of liver transplantation. Ann Transplant 2008;13:37-41. PubMed

44. Namgoong JM, Choi JU, Hwang S, Oh SH, Park GC. Pediatric living donor liver transplantation with homograft replacement of retrohepatic inferior vena cava for advanced hepatoblastoma. Ann Hepatobiliary Pancreat Surg 2019;23:178-82. DOI PubMed PMC

45. Hort A, Karpelowsky J, Shun A, Thomas G. Use of a donor iliac vein graft for reconstruction of the inferior vena cava in liver transplantation for hepatoblastoma with caval extension. Pediatr Transplant 2019;23:e13409. DOI PubMed

46. Chardot C, Saint Martin C, Gilles A, et al. Living-related liver transplantation and vena cava reconstruction after total hepatectomy including the vena cava for hepatoblastoma. Transplantation 2002;73:90-2. DOI PubMed

47. Hasegawa T, Kimura T, Ihara Y, et al. Living-related liver transplantation with removal of inferior vena cava for unresectable hepatoblastoma. Pediatr Transplant 2006;10:521-4. DOI PubMed

48. Uchida H, Fukuda A, Sasaki K, et al. Benefit of early inflow exclusion during living donor liver transplantation for unresectable hepatoblastoma. J Pediatr Surg 2016;51:1807-11. DOI PubMed

49. Herden U, Grabhorn E, Lenhartz H, Kütemeier R, Fischer L. Excellent outcome following liver transplantation for hepatoblastoma using an extensive en bloc hepatectomy technique. Transplant Proc 2019;51:1887-91. DOI PubMed

50. Kueht M, Thompson P, Rana A, Cotton R, O'Mahony C, Goss J. Effects of an early referral system on liver transplantation for hepatoblastoma at Texas Children's Hospital. Pediatr Transplant 2016;20:515-22. DOI PubMed

51. Venkatramani R, Stein JE, Sapra A, et al. Effect of neoadjuvant chemotherapy on resectability of stage III and IV hepatoblastoma. $\mathrm{Br}$ J Surg 2015;102:108-13. DOI PubMed

52. Ruth ND, Kelly D, Sharif K, Morland B, Lloyd C, McKiernan PJ. Rejection is less common in children undergoing liver transplantation for hepatoblastoma. Pediatr Transplant 2014;18:52-7. DOI PubMed

53. Lee WS, Grundy R, Milford DV, et al. Renal function following liver transplantation for unresectable hepatoblastoma. Pediatr Transplant 2003;7:270-6. DOI PubMed

54. Zavala R, Marzouki M, Beaunoyer M, Alvarez F. Glomerular filtration rate in liver transplant for unresectable hepatoblastoma. Pediatr Transplant 2020;24:e13746. DOI PubMed

55. Hendrickson RJ, Sujka J, Fischer R, Manalang M, Daniel J, Andrews WS. Indications and efficacy of conversion from tacrolimus- to sirolimus-based immunosuppression in pediatric patients who underwent liver transplantation for unresectable hepatoblastoma. Pediatr Transplant 2019;23:e13369. DOI PubMed

56. Malek MM, Shah SR, Atri P, et al. Review of outcomes of primary liver cancers in children: our institutional experience with resection and transplantation. Surgery 2010;148:778-82; discussion 782. DOI PubMed

57. Ramos-Gonzalez G, LaQuaglia M, O'Neill AF, et al. Long-term outcomes of liver transplantation for hepatoblastoma: a single-center 14-year experience. Pediatr Transplant 2018:e13250. DOI PubMed

58. Suh MY, Wang K, Gutweiler JR, et al. Safety of minimal immunosuppression in liver transplantation for hepatoblastoma. J Pediatr Surg 2008;43:1148-52. DOI PubMed

59. Faraj W, Dar F, Marangoni G, et al. Liver transplantation for hepatoblastoma. Liver Transpl 2008;14:1614-9. DOI PubMed

60. Mejia A, Langnas AN, Shaw BW, Torres C, Sudan DL. Living and deceased donor liver transplantation for unresectable hepatoblastoma at a single center. Clin Transplant 2005;19:721-5. DOI PubMed

61. Al-oabandi W, Jenkinson H, Buckels J, et al. Orthotopic liver transplantation for unresectable hepatoblastoma: a single center's experience. J Pediatr Surg 1999;34:1261-4. DOI PubMed

62. Sakamoto S, Kasahara M, Mizuta K, et al; Japanese Liver Transplantation Society. Nationwide survey of the outcomes of living donor liver transplantation for hepatoblastoma in Japan. Liver Transpl 2014;20:333-46. DOI PubMed

63. Tiao GM, Bobey N, Allen S, et al. The current management of hepatoblastoma: a combination of chemotherapy, conventional resection, and liver transplantation. J Pediatr 2005;146:204-11. DOI PubMed

64. Ng K, Rana A, Masand P, et al. Fatal central nervous system post-transplant lymphoproliferative disease in a patient who underwent liver transplantation for hepatoblastoma. J Pediatr Gastroenterol Nutr 2018;66:e21-3. DOI PubMed

65. Austin MT, Leys CM, Feurer ID, et al. Liver transplantation for childhood hepatic malignancy: a review of the United Network for Organ Sharing (UNOS) database. J Pediatr Surg 2006;41:182-6. DOI PubMed

66. Zsiros J, Brugieres L, Brock P, et al. Dose-dense cisplatin-based chemotherapy and surgery for children with high-risk hepatoblastoma (SIOPEL-4): a prospective, single-arm, feasibility study. Lancet Oncol 2013;14:834-42. DOI PubMed PMC

67. Yang T, Whitlock RS, Vasudevan SA. Surgical management of hepatoblastoma and recent advances. Cancers (Basel) 2019;11:1944. DOI PubMed PMC

68. Umeda K, Okajima H, Kawaguchi K, et al. Prognostic and therapeutic factors influencing the clinical outcome of hepatoblastoma after liver transplantation: a single-institute experience. Pediatr Transplant 2018;22:e13113. DOI PubMed

69. Triana Junco P, Cano EM, Dore M, et al. Prognostic Factors for Liver Transplantation in Unresectable Hepatoblastoma. Eur J Pediatr 
Surg 2019;29:28-32. DOI PubMed

70. Perilongo G, Brown J, Shafford E, et al; Liver Tumour Study Group of the International Society of Paediatric Oncology (SIOP). Hepatoblastoma presenting with lung metastases: Treatment results of the first cooperative, prospective study of the International Society of Paediatric Oncology on childhood liver tumors. Cancer 2000;89:1845-53. DOI PubMed

71. Otte JB, Meyers R. PLUTO first report. Pediatr Transplant 2010;14:830-5. DOI PubMed

72. Kosola S, Lauronen J, Sairanen H, Heikinheimo M, Jalanko H, Pakarinen M. High survival rates after liver transplantation for hepatoblastoma and hepatocellular carcinoma. Pediatr Transplant 2010;14:646-50. DOI PubMed

73. Browne M, Sher D, Grant D, et al. Survival after liver transplantation for hepatoblastoma: a 2-center experience. J Pediatr Surg 2008;43:1973-81. DOI PubMed

74. Khan AS, Brecklin B, Vachharajani N, et al. Liver Transplantation for malignant primary pediatric hepatic tumors. J Am Coll Surg 2017;225:103-13. DOI PubMed

75. Kim T, Kim DY, Kim KM, et al. Pediatric liver transplantation for hepatoblastoma: a single center experience. Transplant Proc 2012;44:523-5. DOI PubMed

76. Kasahara M, Ueda M, Haga H, et al. Living-donor liver transplantation for hepatoblastoma. Am J Transplant 2005;5:2229-35. DOI PubMed

77. Angelico R, Grimaldi C, Gazia C, et al. How do synchronous lung metastases influence the surgical management of children with hepatoblastoma? Cancers (Basel) 2019;11:1693. DOI PubMed PMC

78. Srinivasan P, McCall J, Pritchard J, et al. Orthotopic liver transplantation for unresectable hepatoblastoma. Transplantation 2002;74:652-5. DOI PubMed

79. Isono K, Ohya Y, Lee KJ, et al. Pretransplant trends in $\alpha$-fetoprotein levels as a predictor of recurrence after living donor liver transplantation for unresectable hepatoblastoma: a single-institution experience. Pediatr Transplant 2018;22:e13221. DOI PubMed

80. Lauferman L, Halac E, Aredes D, et al. Prognostic factors for event-free survival in liver transplantation for hepatoblastoma: a singlecenter experience. Pediatr Transplant 2019;23:e13581. DOI PubMed

81. Czauderna P, Mackinlay G, Perilongo G, et al; Liver Tumors Study Group of the International Society of Pediatric Oncology. Hepatocellular carcinoma in children: results of the first prospective study of the International Society of Pediatric Oncology group. $J$ Clin Oncol 2002;20:2798-804. DOI PubMed

82. D'Souza AM, Towbin AJ, Gupta A, et al. Clinical heterogeneity of pediatric hepatocellular carcinoma. Pediatr Blood Cancer 2020;67:e28307. DOI PubMed

83. Mazzaferro V, Llovet JM, Miceli R, et al. Predicting survival after liver transplantation in patients with hepatocellular carcinoma beyond the Milan criteria: a retrospective, exploratory analysis. Lancet Oncol 2009;10:35-43. DOI PubMed

84. Schmid I, von Schweinitz D. Pediatric hepatocellular carcinoma: challenges and solutions. J Hepatocell Carcinoma 2017;4:15-21. DOI PubMed PMC

85. Sugawara Y. Living-donor liver transplantation for patients with hepatocellular carcinoma in Japan: current situations and challenge. Hepatobiliary Pancreat Dis Int 2020;19:1-2. DOI PubMed

86. Ville de Goyet J, Meyers RL, Tiao GM, Morland B. Beyond the Milan criteria for liver transplantation in children with hepatic tumours. Lancet Gastroenterol Hepatol 2017;2:456-62. DOI PubMed

87. Triana P, Dore M, Romo MM, et al. Hepatocellular carcinoma: referral to a transplantation unit. Eur J Pediatr Surg 2017;27:16-9. DOI PubMed

88. Ismail H, Broniszczak D, Kaliciński P, et al. Liver transplantation in children with hepatocellular carcinoma. Do Milan criteria apply to pediatric patients? Pediatr Transplant 2009;13:682-92. DOI PubMed

89. Ziogas IA, Benedetti DJ, Matsuoka LK, et al. Surgical management of pediatric hepatocellular carcinoma: an analysis of the National Cancer Database. J Pediatr Surg 2021;56:772-7. DOI PubMed

90. Reyes JD, Carr B, Dvorchik I, et al. Liver transplantation and chemotherapy for hepatoblastoma and hepatocellular cancer in childhood and adolescence. J Pediatr 2000;136:795-804. PubMed

91. Kelly D, Sharif K, Brown RM, Morland B. Hepatocellular carcinoma in children. Clin Liver Dis 2015;19:433-47. DOI PubMed

92. Ziogas IA, Ye F, Zhao Z, et al. Population-based analysis of hepatocellular carcinoma in children: identifying optimal surgical treatment. J Am Coll Surg 2020;230:1035-44.e3. DOI PubMed

93. Baumann U, Adam R, Duvoux C, et al; European Liver and Intestine Transplant Association. Survival of children after liver transplantation for hepatocellular carcinoma. Liver Transpl 2018;24:246-55. DOI PubMed

94. Ozçay F, Canan O, Bilezikçi B, Torgay A, Karakayali H, Haberal M. Effect of living donor liver transplantation on outcome of children with inherited liver disease and hepatocellular carcinoma. Clin Transplant 2006;20:776-82. DOI PubMed

95. Llovet JM, Ricci S, Mazzaferro V, et al; SHARP Investigators Study Group. Sorafenib in advanced hepatocellular carcinoma. $N$ Engl J Med 2008;359:378-90. DOI PubMed

96. Liang $\mathrm{W}, \mathrm{Wu} \mathrm{L}$, Ling X, et al. Living donor liver transplantation versus deceased donor liver transplantation for hepatocellular carcinoma: a meta-analysis. Liver Transpl 2012;18:1226-36. DOI PubMed

97. Katz SC, Shia J, Liau KH, et al. Operative blood loss independently predicts recurrence and survival after resection of hepatocellular carcinoma. Ann Surg 2009;249:617-23. DOI PubMed

98. Nishizaki T, Matsumata T, Kanematsu T, Yasunaga C, Sugimachi K. Surgical manipulation of VX2 carcinoma in the rabbit liver evokes enhancement of metastasis. J Surg Res 1990;49:92-7. DOI PubMed

99. Beaunoyer M, Vanatta JM, Ogihara M, et al. Outcomes of transplantation in children with primary hepatic malignancy. Pediatr Transplant 2007;11:655-60. DOI PubMed 
100. Ravaioli M, Ercolani G, Neri F, et al. Liver transplantation for hepatic tumors: a systematic review. World J Gastroenterol 2014;20:5345-52. DOI PubMed PMC

101. Geissler EK, Schnitzbauer AA, Zülke C, et al. Sirolimus use in liver transplant recipients with hepatocellular carcinoma: a randomized, multicenter, open-label phase 3 trial. Transplantation 2016;100:116-25. DOI PubMed PMC

102. Koneru B, Flye MW, Busuttil RW, et al. Liver transplantation for hepatoblastoma. The American experience. Ann Surg 1991;213:118-21. DOI PubMed PMC

103. Cillo U, Ciarleglio FA, Bassanello M, et al. Liver transplantation for the management of hepatoblastoma. Transplant Proc 2003;35:2983-5. DOI PubMed

104. Casas-Melley AT, Malatack J, Consolini D, et al. Successful liver transplant for unresectable hepatoblastoma. J Pediatr Surg 2007;42:184-7. DOI PubMed

105. Héry G, Franchi-Abella S, Habes D, et al. Initial liver transplantation for unresectable hepatoblastoma after chemotherapy. Pediatr Blood Cancer 2011;57:1270-5. DOI PubMed

106. Barrena S, Hernandez F, Miguel M, et al. High-risk hepatoblastoma: results in a pediatric liver transplantation center. Eur J Pediatr Surg 2011;21:18-20. DOI PubMed

107. Kirnap M, Ayvazoglu Soy E, Ozcay F, Moray G, Ozdemir BH, Haberal M. Pediatric liver transplant for hepatoblastoma: a singlecenter experience. Exp Clin Transplant 2017;15:50-2. DOI PubMed

108. Ezekian B, Mulvihill MS, Schroder PM, et al. Improved contemporary outcomes of liver transplantation for pediatric hepatoblastoma and hepatocellular carcinoma. Pediatr Transplant 2018;22:e13305. DOI PubMed

109. Okur MH, Yankol Y, Cimşit B, et al. Liver transplant in children with hepatoblastoma. Exp Clin Transplant 2019;17:644-7. DOI PubMed

110. Feng J, He Y, Wei L, et al. Assessment of survival of pediatric patients with hepatoblastoma who received chemotherapy following liver transplant or liver resection. JAMA Netw Open 2019;2:e1912676. DOI PubMed PMC

111. Arikan C, Kilic M, Nart D, et al. Hepatocellular carcinoma in children and effect of living-donor liver transplantation on outcome. Pediatr Transplant 2006;10:42-7. DOI PubMed

112. Sevmis S, Karakayali H, Ozçay F, et al. Liver transplantation for hepatocellular carcinoma in children. Pediatr Transplant 2008;12:52-6. DOI PubMed

113. Romano F, Stroppa P, Bravi M, et al. Favorable outcome of primary liver transplantation in children with cirrhosis and hepatocellular carcinoma. Pediatr Transplant 2011;15:573-9. DOI PubMed

114. Weiss KE, Sze DY, Rangaswami AA, et al. Transarterial chemoembolization in children to treat unresectable hepatocellular carcinoma. Pediatr Transplant 2018;22:e13187. DOI PubMed 